\title{
Validity of the Clinical Frailty Scale in Korean older patients at a geriatric clinic
}

\author{
Hee-Won Jung 1 , Il-Young Jang 1 , Ji Yeon Back¹, Seunghyun Park ${ }^{2}$, Chan Mi Park ${ }^{3}$, Seung Jun Han ${ }^{4}$, and \\ Eunju Lee ${ }^{1}$
}

\begin{abstract}
${ }^{1}$ Division of Geriatrics, Department of Internal Medicine, Asan Medical Center, University of Ulsan College of Medicine, Seoul; ${ }^{2}$ Department of Health Promotion and Management, National Health Insurance Service, Wonju; ${ }^{3}$ Department of Family Medicine, Korea University Anam Hospital, Seoul; ${ }^{4}$ Department of Internal Medicine, Hospital Medicine Center, Seoul National University Hospital, Seoul, Korea
\end{abstract}

Received: December 8, 2020 Revised : December 18, 2020 Accepted: December 22, 2020

\author{
Correspondence to \\ Eunju Lee, M.D. \\ Division of Geriatrics, \\ Department of Internal \\ Medicine, Asan Medical Center, \\ University of Ulsan College of \\ Medicine, 88 Olympic-ro 43-gil, \\ Songpa-gu, Seoul 05505, Korea \\ Tel: $+82-2-3010-3308$ \\ Fax: $+82-2-2045-4268$ \\ E-mail: eunjulee@amc.seoul.kr \\ https://orcid.org/0000-0003- \\ 4612-0625
}

Background/Aims: We aimed to assess the validity of the Korean translated version of the Clinical Frailty Scale (CFS) in determining the frailty status in geriatric outpatients.

Methods: The records of 123 ambulatory outpatients who had undergone CFS and comprehensive geriatric assessments (CGAs) including measurements for the Cardiovascular Health Study (CHS) frailty scale and the frailty index (CGA-FI) were analyzed. Correlations between CFS, CHS frailty scale, and CGA-FI were assessed. The ability of CFS to classify frailty status was calculated using the CHS frailty scale and CGA-FI as references.

Results: The mean CFS score was 3.2 in the study population, with a mean age of 77.49 years $(45.5 \%$ men). Individuals with higher CFS scores were older, had a greater burden of chronic diseases, and worse daily functions and cognitive performance. CFS scores positively correlated with CGA-FI $(B=0.78, p<0.001)$ and CHS frailty scale $(B=0.67, p<0.001)$ scores. For CFS, $C$-statistics to classify frailty by CGA-FI and CHS scale were 0.905 and 0.826 , respectively. The cut-off value of CFS $\geq 4$ maximized Youden's J to classify frailty by both the CHS scale and CGAFI.

Conclusions: The CFS is a valid screening tool to assess the frailty status in outpatients of a geriatric clinic in Korea. As a simple and quick measure, the CFS may facilitate frailty assessments in real-world clinical practice.

Keywords: Diagnosis; Frailty; Aged; Quality improvement; Geriatric assessment

\section{INTRODUCTION}

Frailty, a common geriatric syndrome that is closely related to human aging, is defined as a state of decreased physiological reserve and increased vulnerability to internal or external stressors [1]. Several studies have shown the impacts of frailty on the outcomes of fall, functional decline, institutionalization, and mortality in both community and hospital settings $[2,3]$, with growing research interests in assessing frailty in various clinical conditions even among specialties other than geriatrics [4]. By virtue of its outcome prediction ability, frailty is factored in the decision-making processes of several clinical conditions [5,6]. Furthermore, recent studies have shown the dynamic characteristics of frailty [7] and suggested that frailty can be improved with appropriate intervention strategies [8]. Therefore, frailty is a crucial clinical outcome measure as well as an outcome predictor.

Identifying frailty status can be the first step to pro- 
vide centered, tailored care for older adults through multidimensional assessment and intervention [9,10]. However, frailty statuses have been not commonly assessed in most acute hospitals, including those in Korea. In acute care settings, performing comprehensive geriatric assessments (CGAs) for older patients is less feasible as CGAs frequently take $>30$ minutes for a single patient. To address this unmet need, several screening measures of frailty for older adults have been developed and validated [11-14]. Among these instruments, the ones requiring physical performance assessments might be less applicable for acute hospital settings where patients experience sudden deconditioning due to acute illnesses. Moreover, questionnaires validated in community-dwelling populations or primary care settings might be less reliable for identifying the vulnerable populations in acute or chronic hospitals.

The Clinical Frailty Scale (CFS), a simple tool with brief descriptors and pictographs, to track frailty index, was developed to facilitate a broader application of frailty in real-world clinical practices [15]. Following an initial validation of outcome prediction abilities in a community-dwelling population [15], numerous studies have employed this scale and found clinical validity in its outcome prediction, in settings ranging from long-term care facilities to emergency departments [16]. Hence, CFS has been used in wide range of clinical settings in western countries, in clinical decision making and outcome prediction [17-19]. Furthermore, CFS has been even suggested as a measure in evaluating older people or allocating scarce health resource in coronavirus disease 2019 (COVID-19) pandemic [5,17]. Despite its validity and wide-adaptability, to the best of our knowledge, the screening value of the CFS has been not yet reported in the Korean population. Therefore, in this study, we aimed to assess the screening ability of the CFS for frailty determined by two widely used measures of frailty, the Cardiovascular Health Study (CHS) frailty scale and the CGA-frailty index (CGA-FI), in outpatients of a geriatric clinic in a tertiary hospital in Korea.

\section{METHODS}

\section{Study design and population}

This was a cross-sectional analysis that used records of
123 outpatients who had undergone CFS and CGA assessments between February 2019 and April 2020 in a geriatric clinic at Asan Medical Center, Seoul, Korea. We included community-dwelling patients who were ambulatory with or without walking aids and were able to communicate with the examiners and agreed to participate in the prospective registry of CGA and aging biomarker study. Further, we excluded patients with apparent life expectancies of less than 1 year due to malignancies, patients with symptomatic heart failure or end-stage renal disease, patients unable to walk without assistance, and patients with cognitive dysfunction who could not follow the instructions of the physical performance tests.

\section{The CFS}

We used a 9-score version of the original CFS (version 2.0) that translated into Korean by English-proficient geriatrician and reviewed by another clinical geriatrician who had clinical experience in both Korean and United States, and an independent bilingual geriatrician educated in United States (Supplementary Table 1). After this process, words and descriptions were further reviewed for cultural aspects of Korean older people and clinical usability, by clinical geriatricians and nurses. CFS was administered by the experienced nurses in the geriatric clinic by interviewing the patients and their family members, during regular CGA. Most probable state of general health status during recent 1 to 2 weeks was selected in the scale.

\section{The CGA-FI}

The CGA included the common geriatric domains of comorbidities, fall history, polypharmacy, nutrition risk, mobility, cognition, and physical performance. The comorbidities were identified by reviewing medical records and through patient interviews. Polypharmacy was defined as the usage of five or more different medications per day. Mobility and basic physical activities were assessed using items suggested by Rosow and Breslau [20] and Nagi [21], respectively. The presence of fall history in the previous 12 months was assessed. Cognitive function was assessed by the Korean version of the Mini-Mental Status Examination (MMSE), and cognitive impairment was defined as an MMSE score of less than 24 [22]. The participants were interviewed on 
difficulties in performing activities of daily living (ADL) functions (dressing, washing, bathing, eating, moving, and using the bathroom) and instrumental ADL functions (using transportation, using phones, buying groceries, managing medications, managing finances, preparing foods, performing basic household chores, and washing clothes). Individuals with impairments in 1 or more items were regarded to have disabilities in ADL or IADL. The grip strength of the dominant side was measured by a hydraulic dynamometer (Jamar, Patterson Medical, Warrenville, IL, USA). Four-meter usual gait speed and 5-time chair stand test were assessed using an electronic SPPB toolkit (eSPPB, Dyphi Inc., Daejeon, Korea). From these parameters of CGA, we established a 50-item CGA-FI from the components of CGA (Supplementary Table 2) that had been established in a standardized manner and used in other studies $[4,23,24]$. The sums of the scores of each item were calculated and divided by the total number of available items ( 50 if no items were missed), to produce CGA-FIs ranging from o (best) to 1 (worst). We considered frailty indices of 0.25 and higher as frail [3].

\section{The CHS frailty scale}

The frailty phenotype was evaluated by the CHS frailty scale [25] that comprised the following items: (1) exhaustion determined by a patient health questionnaire-2 screening test total score $>2$ [26]; (2) low physical activity defined as a weekly activity amount $<494.65 \mathrm{kcal}$ for men and $<283.50 \mathrm{kcal}$ for women using the International Physical Activity Questionnaire [27]; (3) low grip strength by the grip strength of the lowest quintile corresponding to sex and body mass index [27]; (4) slowness by the gait speed of the lowest quintile corresponding to sex and height [27]; and (5) unintentional weight loss of $>4.5 \mathrm{~kg}$ in the previous 12 months. For the CHS frailty score, the number of positive items was calculated and individuals with CHS frailty scores of 3 and higher were considered to be frail.

\section{Statistical analysis}

Independent $t$ test and chi-square test or Fischer's exact test were used to compare the characteristics between the patients with CFS scores $<4$ (lower CFS group) and $\geq 4$ (higher CFS group), by taking into account the distribution of the CFS scores in the study population. Ad- ditionally, skewness tests and histograms were used to assess the distributions of frailty measures in the study population. We adopted Consensus-based Standards for the selection of health Measurement Instruments terms of construct and criterion validity to analyze and describe the validity of CFS in assessing the frailty status [28]. Using linear regression analyses, correlations between the CFS scores and geriatric parameters or the items of the CHS frailty scale were assessed, and standardized beta [B] was calculated as the regression coefficient. The correlations between the CFS scores, CHS frailty score, and frailty index were evaluated using linear regression analysis, and B was calculated as the regression coefficient. C-statistics were calculated for CFS scores to determine frailty by the CHS frailty scale and the frailty index using receiver operating characteristic (ROC) analysis. Additionally, sensitivities and specificities for specific CFS scores to classify frailty by the CHS frailty scale and frailty index were calculated. To suggest cut-offs of CFS scores to suspect frailty, we calculated Youden's J (sensitivity + specificity-1). We considered two-sided $p$ values $<0.05$ to be statistically significant and used Stata version 16.0 (Stata Corp., College Station, TX, USA) for analyses.

\section{Ethics statement}

The study protocol was reviewed and approved by the Institutional Review Board of Asan Medical Center (2018-0673) and complied with the ethical rules for human experimentation stated in the Declaration of Helsinki [29]. Written informed consent was acquired from the participants or their proxies.

\section{RESULTS}

\section{Basic demographic and clinical characteristics}

In the study population of 123 individuals, the mean age was 77.49 years, and 56 individuals (45.5\%) were men. The mean \pm standard deviation CFS score was $3.2 \pm 1.1$ and the mean frailty index was $0.15 \pm 0.09$. Most of the items included in the frailty index were present for the 123 individuals, data of physical activity and MMSE were available in 119 people, and those of BMI and five times chair stand test were available in 122. The mean CHS frailty scale score in the study population was $1.8 \pm 1.2$. 


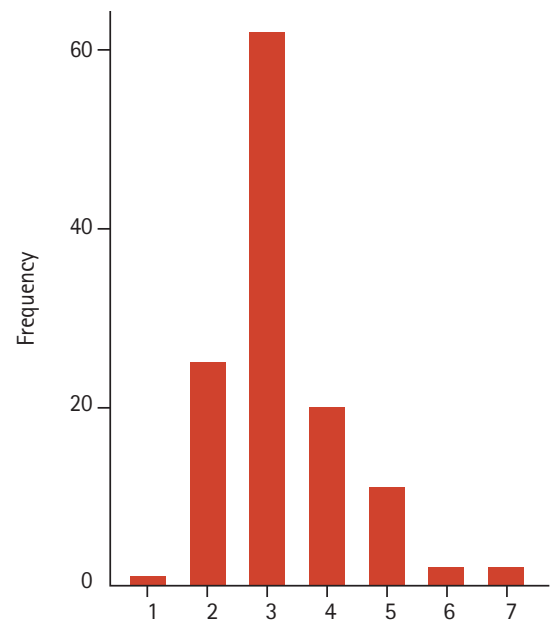

A

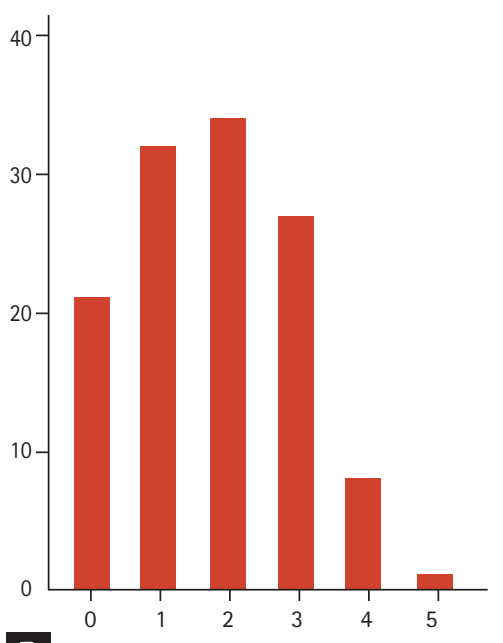

B

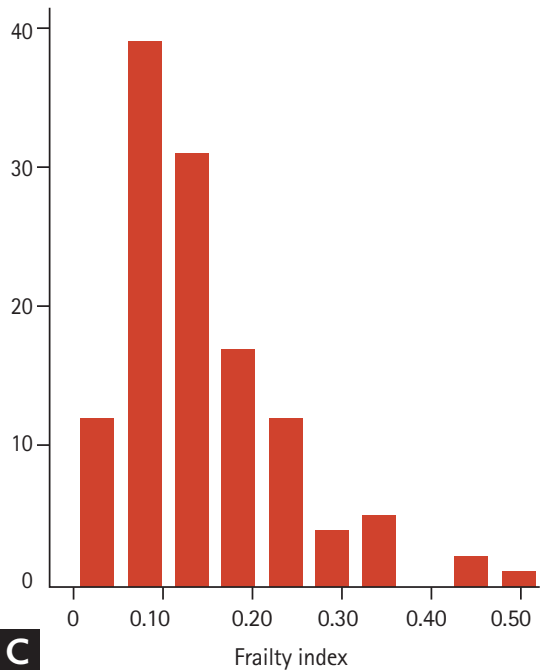

Figure 1. Population distributions by specific scores of the clinical frailty scale (A), the Cardiovascular Health Study (CHS) frailty scale (B), and a histogram of the frailty index (C) in the study population.

Table 1. Basic characteristics of the study population according to the CFS scores

\begin{tabular}{|c|c|c|c|}
\hline Characteristic & Lower CFS (CFS score < 4) & Higher CFS (CFS score $\geq 4$ ) & $p$ value \\
\hline Age, yr & $76.2 \pm 6.3$ & $88.8 \pm 6.1$ & $<0.001$ \\
\hline Male sex & $45(51.1)$ & $11(31.4)$ & 0.048 \\
\hline BMI, kg/m² & $24.1 \pm 3.4$ & $22.9 \pm 4.0$ & 0.089 \\
\hline Number of chronic diseases & $3 \cdot 3 \pm 1.5$ & $4.7 \pm 1.9$ & $<0.001$ \\
\hline Hypertension & $54(61.4)$ & $24(68.6)$ & 0.454 \\
\hline Diabetes & $23(26.1)$ & $12(34 \cdot 3)$ & 0.366 \\
\hline Cancer & $9(10.2)$ & $1(2.9)$ & $0.279^{\mathrm{a}}$ \\
\hline Coronary artery disease & $25(28.4)$ & $6(17 \cdot 1)$ & 0.194 \\
\hline ADL abnormality & $5(5 \cdot 7)$ & $7(20.0)$ & 0.016 \\
\hline IADL abnormality & $8(9.1)$ & $17(48.6)$ & $<0.001$ \\
\hline Cognitive impairment & $18(20.5)$ & $15(42.9)$ & 0.011 \\
\hline CGA-FI & $0.10 \pm 0.05$ & $0.17 \pm 0.10$ & $<0.001$ \\
\hline CHS frailty scale score & $1.4 \pm 1.1$ & $2.8 \pm 0.8$ & $<0.001$ \\
\hline
\end{tabular}

Values are presented as mean \pm standard deviation or number (\%).

CFS, Clinical Frailty Scale; BMI, body mass index; ADL, activities of daily living; ; IADL, instrumental activities of daily living; CGA-FI, comprehensive geriatric assessment-frailty index; CHS, Cardiovascular Health Study.

${ }^{a}$ Fisher's exact test $p$ value.

By skewness test, both CFS scores and frailty index were right-skewed (both $p<0.001$ ) whereas CHS frailty scale scores were not skewed $(p=0.366)$. Distributions of these three frailty measures are shown in Fig. 1.

The study population was divided into two groups
(CFS score $<4$ and $\geq 4$ ), considering the mean value of CFS. As shown in Table 1, individuals with higher CFS scores tended to be older, were more likely to be women, had a greater burden of chronic diseases, had worse daily functions and cognitive performances, and higher 


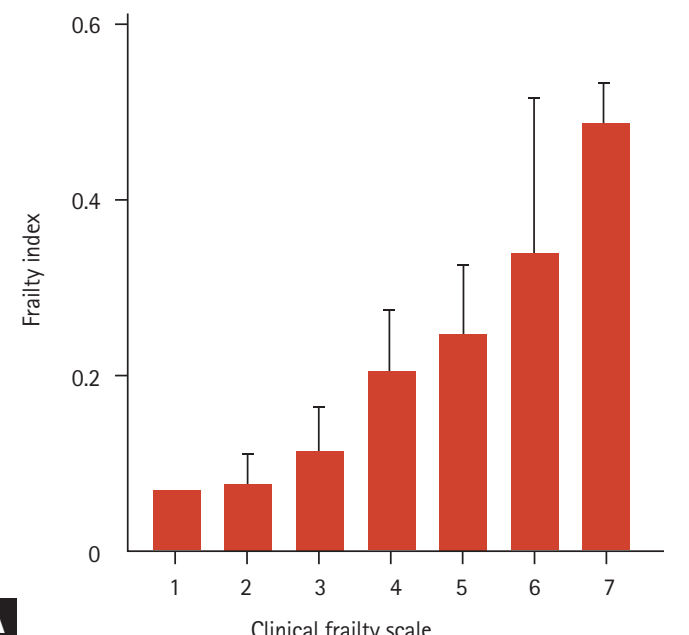

A

Clinical frailty scale

B

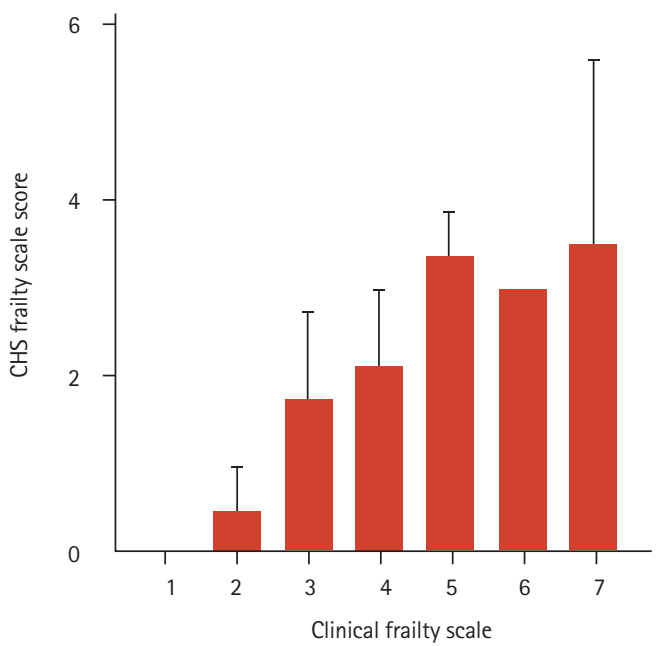

Figure 2. Means (bars) and standard deviations (whiskers) of the frailty index (A) and the Cardiovascular Health Study (CHS) frailty scale scores (B) according to the clinical frailty scale scores.

frailty indices and CHS frailty scale scores.

\section{Content validity of the CFS as a frailty measure}

By linear regression, CFS scores significantly correlated with the geriatric parameters of $\mathrm{ADL}(\mathrm{B}=0.54, p<$ $0.001)$, IADL ( $\mathrm{B}=0.64, p<0.001)$, MMSE score $(\mathrm{B}=0.38, p$ $<0.001)$, and the number of chronic diseases $(B=0.34, p<$ o.001). Additionally, CFS scores significantly correlated positively with the CHS frailty scale items of exhaustion ( $\mathrm{B}=0.4 \mathrm{O}, p<0.001)$, low physical activity $(\mathrm{B}=0.53, p<$ $0.001)$, slow gait speed $(\mathrm{B}=0.43, p<0.001)$, and weakness $(\mathrm{B}=0.51, p<0.001)$. However, the correlation between the CFS scores and weight loss was not significant $(\mathrm{B}=$ $0.09, p=0.342$ ).

\section{Construct validity of CFS with the CGA-FI and CHS frailty scale}

Fourteen and thirty-six individuals were frail, as determined by the CGA-FI and CHS frailty scale respectively. By linear regression, CFS scores correlated with CGA-FI $(\mathrm{B}=0.78, p<0.001)$ and $\mathrm{CHS}$ frailty scale scores $(\mathrm{B}=0.67$, $p<0.001)$. Corresponding distributions of CGA-FI and CHS frailty scale scores are shown in Fig. 2. The associations of CFS scores with CGA-FI and CHS frailty scale scores remained significant with age and sex introduced as covariables $(\mathrm{B}=0.72, \mathrm{p}<0.001$; and $\mathrm{B}=0.60, \mathrm{p}<0.001$, respectively).

\section{Criterion validity of CFS for frailty status by the frail- ty index and CHS frailty scale}

ROC analysis was used to assess the discrimination ability of CFS for classifying frailty statuses (Fig. 3). For CFS, the C-statistics to classify frailty by CGA-FI and CHS scale were 0.905 (95\% confidence interval [CI], 0.833 to 0.977 ) and 0.826 (95\% CI, 0.854 to 0.897 ), respectively. The sensitivity and specificity for each value of CFS are shown in Table 2, and the cut-off value of CFS score $\geq 4$ maximized Youden's J to classify frailty by both the CHS scale and CGA-FI.

\section{DISCUSSION}

In this cross-sectional study, we found that the CFS was correlated with geriatric parameters and two measures of frailty, the CHS frailty scale reflecting the frailty phenotype and CGA-FI reflecting the deficit accumulation model, in Korean outpatients who visited a geriatric clinic. Moreover, the discrimination ability of CFS to classify the frailty status was excellent for the frailty phenotype and outstanding for the frailty index [30]. To the authors' knowledge, this study is the first to report the clinical validity of the Korean translated version of the CFS.

Despite numerous efforts to develop valid and feasi- 

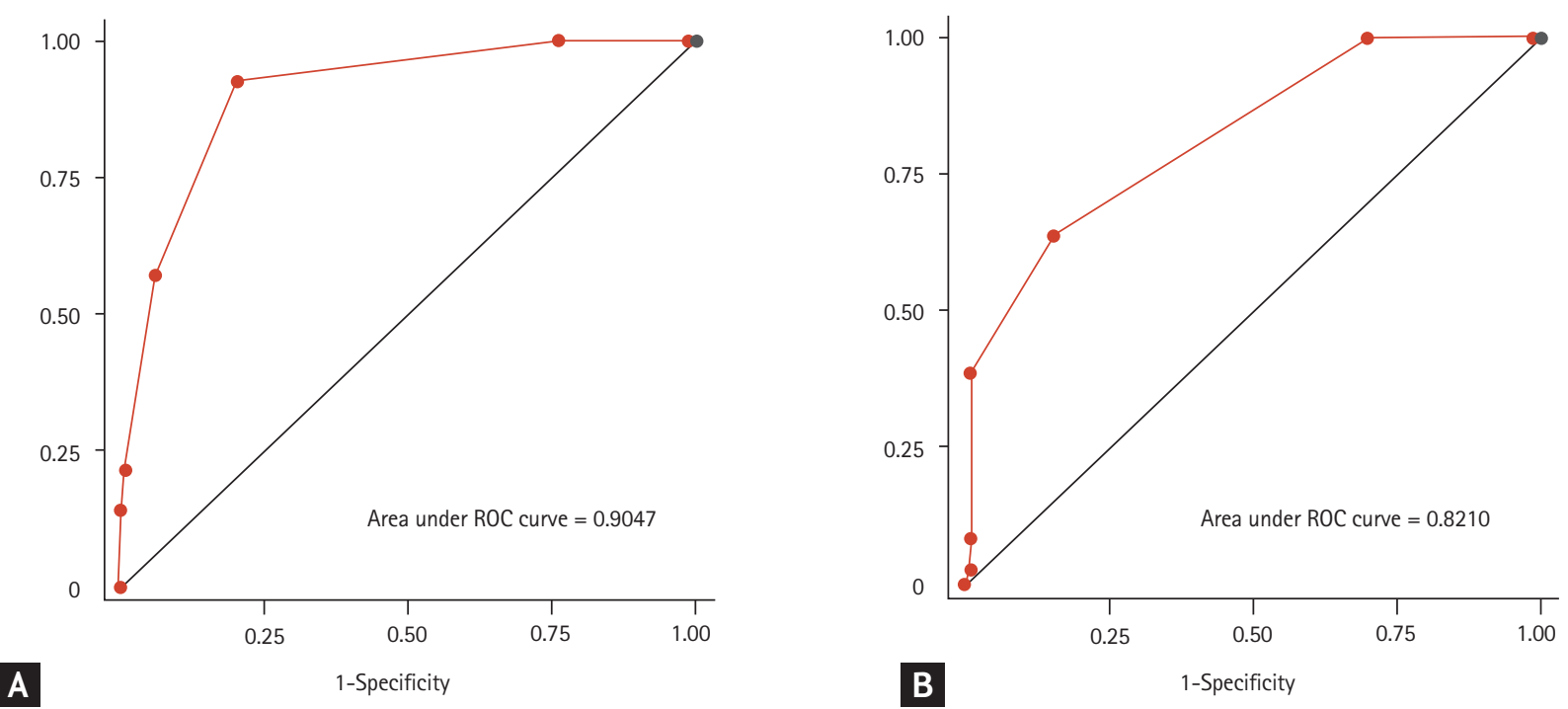

Figure 3. Receiver operating characteristic (ROC) curves to detect the frailty status using the clinical frailty scale with the frailty index (A) and the Cardiovascular Health Study (CHS) frailty scale (B) as references.

Table 2. Table for sensitivity and specificity by corresponding CFS scores to determine the frail status by the CGA-FI and the CHS frailty scale

\begin{tabular}{|c|c|c|c|c|}
\hline \multirow{2}{*}{$\operatorname{CFS}(\geq)$} & \multicolumn{2}{|c|}{ CGA-FI } & \multicolumn{2}{|c|}{ CHS frailty scale } \\
\hline & Sensitivity, \% & Specificity, \% & Sensitivity, \% & Specificity, \% \\
\hline 1 & 100.0 & 0.0 & 100.0 & 0.0 \\
\hline 2 & 100.0 & 0.9 & 100.0 & 1.2 \\
\hline 3 & 100.0 & 23.9 & 100.0 & 29.9 \\
\hline 4 & $93 \cdot 9$ & 79.8 & 63.9 & 86.2 \\
\hline 5 & 57.1 & 93.6 & 38.9 & 98.9 \\
\hline 6 & 21.4 & 99.1 & 8.3 & 98.9 \\
\hline 7 & $14 \cdot 3$ & 100.0 & 2.8 & 100.0 \\
\hline
\end{tabular}

CFS, Clinical Frailty Scale; CGA-FI, comprehensive geriatric assessment-frailty index; CHS, Cardiovascular Health Study.

ble screening instruments for frailty, instruments have distinct drawbacks in clinical use. Screening questionnaires are usually validated in community-based studies rather than in acute or chronic care situations for older adults with complex care needs [14], and they might not be suitable to capture the diverse spectrum of disabilities and comorbidities. For instance, the question about loss of body weight to screen the risk of malnutrition can be only effective if the person is in the course of losing weight, and it might not be able to capture an advanced frailty status with already decreased lean mass. Although physical performance measures can be assessed objec- tively and are excellent in determining the frailty status with high prediction ability for adverse outcomes in older adults [31], issues exist due to the dynamic range of tools and feasibilities in applying them in varying circumstances of real-world clinical practice. For example, usual gait speed and the timed up and go test are excellent to screen the vulnerable population in primary care or community setting [32-34]; however, these examinations are less feasible in acutely ill patients with tethers (e.g., intravenous access lines, urinary catheters, and endotracheal tubes) or unstable vital signs. Additionally, these physical performance measures are less likely to 
provide additional information for patients with apparent limitations in mobility both in acute and chronic care settings [35].

This study was performed to probe the possibility of using CFS in a Korean tertiary hospital for detecting and managing frailty in our hospital with the CFS as an initial screening measure. As a tool validated in various environments including emergency departments, intensive care units, and chronic care facilities, the authors believe that the CFS can be used as a tool of prognostication and a screening measure to identify individuals who are susceptible to develop complications in acute care settings [5]. Furthermore, with the rising evidence supporting the clinical efficacy and the cost-effectiveness of the CGA in acutely admitted patients [36], the CFS can be used as an initial rapid-screening test to identify populations who might be benefited from CGA and downstream domain-specific, patient-centered interventions to improve the clinical outcomes of older patients with complex care needs [10].

The adoption of the CFS can be especially valuable as a functional assessment measure at care transition in hospitals, while there is still a paucity of literature showing real world adoption of CFS in Korea in this setting. In older patients, the interactions between underlying diseases, disabilities, and physical or cognitive performance affect not only care needs in welfare aspects but also clinical outcomes. Consequently, older patients might be stranded in acute wards with unmet and unaddressed needs for functional and social issues even after the acute medical problems resolve, increasing both lengths of stays and possibilities of unwanted geriatric or iatrogenic complications. Since the CFS focuses on the spectrums of generalized functional status among older adults on top of physical performance, this instrument might be used as a facile communication tool linking medical problems and functional care needs. With researchers currently developing an electronic pathway using CFA as an initial screening measure, clinical benefits of CFS in care coordination can be evaluated further in the future. Hospital and community-based care resources, filling the current gap between medical care and welfare in older adults, and making care transitions more efficient and effective.

Since this was a cross-sectional analysis of a small number of outpatients who visited a geriatric outpa- tient clinic of a tertiary hospital, some limitations exist. Outcome validity could not be assessed due to the study design. Additionally, the validities of the CFS in inpatients or patients in other care settings in Korea cannot be assured by the current data. A recently published that performed in parallel with the participation of authors of the present study focusing on the outcome relevance of the CFS in acutely hospitalized patients in a different hospital may supplement the limitations of the present study [37].

In conclusion, the CFS correlated with two widely studied frailty measures, CHS frailty scale and frailty index, in ambulatory outpatients of a geriatric clinic in a Korean tertiary hospital, and was able to classify frailty status as a screening measure. As it is a simple and quick measuring tool, the CFS may alleviate the existing barriers in assessing frailty in real-world clinical practice.

\section{KEY MESSAGE}

1. The Korean translated version of the Clinical Frailty Scale (CFS) correlated with common geriatric parameters in comprehensive geriatric assessments in outpatients of a geriatric clinic.

2. The discrimination ability of the CFS to classify the frailty status was excellent for the frailty phenotype and outstanding for the frailty index.

3. As a simple and quick measuring tool, the CFS may alleviate the existing barriers in assessing frailty in real-world clinical practice

\section{Conflict of interest}

No potential conflict of interest relevant to this article was reported.

\section{Acknowledgments}

This study was supported by a grant (2018IFo413) from the Asan Institute for Life Science, Asan Medical Center, Seoul, Republic of Korea. 


\section{REFERENCES}

1. Dent E, Martin FC, Bergman H, Woo J, Romero-Ortuno R, Walston JD. Management of frailty: opportunities, challenges, and future directions. Lancet 2019;394:1376-1386.

2. Kim SW, Han HS, Jung HW, et al. Multidimensional frailty score for the prediction of postoperative mortality risk. JAMA Surg 2014;149:633-640.

3. Jang IY, Lee E, Lee H, et al. Characteristics of sarcopenia by European consensuses and a phenotype score. J Cachexia Sarcopenia Muscle 2020;11:497-504.

4. Kim DH, Afilalo J, Shi SM, et al. Evaluation of changes in functional status in the year after aortic valve replacement. JAMA Intern Med 2019;179:383-391.

5. Rockwood K, Theou O. Using the Clinical Frailty Scale in allocating scarce health care resources. Can Geriatr J 2020;23:210-215.

6. Curtin D, Gallagher P, O'Mahony D. Deprescribing in older people approaching end-of-life: development and validation of STOPPFrail version 2. Age Ageing 2021;50:465-471.

7. Jang IY, Jung HW, Lee HY, Park H, Lee E, Kim DH. Evaluation of clinically meaningful changes in measures of frailty. J Gerontol A Biol Sci Med Sci 2020;75:1143-1147.

8. Jang IY, Jung HW, Park H, et al. A multicomponent frailty intervention for socioeconomically vulnerable older adults: a designed-delay study. Clin Interv Aging 2018;13:1799-1814.

9. Jung HW. Visualizing domains of comprehensive geriatric assessments to grasp frailty spectrum in older adults with a radar chart. Ann Geriatr Med Res 2020;24:55-56.

10. Lee H, Lee E, Jang IY. Frailty and comprehensive geriatric assessment. J Korean Med Sci 2020;35:e16.

11. Jung HW, Yoo HJ, Park SY, et al. The Korean version of the FRAIL scale: clinical feasibility and validity of assessing the frailty status of Korean elderly. Korean J Intern Med 2016;31:594-6oo.

12. Jung HW, Kang MG, Choi JY, et al. Simple method of screening for frailty in older adults using a chronometer and tape measure in clinic. J Am Geriatr Soc 2018;66:157160.

13. Kim S, Jung HW, Won CW. What are the illnesses associated with frailty in community-dwelling older adults: the Korean Frailty and Aging Cohort Study. Korean J Intern Med 2020;35:1004-1013.

14. Jung HW, Kim S, Won CW. Validation of the Korean
Frailty Index in community-dwelling older adults in a nationwide Korean Frailty and Aging Cohort study. Korean J Intern Med 2021;36:456-466.

15. Rockwood K, Song X, MacKnight C, et al. A global clinical measure of fitness and frailty in elderly people. CMAJ 2005;173:489-495.

16. Church S, Rogers E, Rockwood K, Theou O. A scoping review of the Clinical Frailty Scale. BMC Geriatr 2020;20:393.

17. Chong E, Chan M, Tan HN, Lim WS. COVID-19: use of the Clinical Frailty Scale for critical care decisions. J Am Geriatr Soc 2020;68:E30-E32.

18. Chong E, Ho E, Baldevarona-Llego J, et al. Frailty in hospitalized older adults: comparing different frailty measures in predicting short- and long-term patient outcomes. J Am Med Dir Assoc 2018;19:450-457.

19. Moorhouse P, Mallery LH. Palliative and therapeutic harmonization: a model for appropriate decision-making in frail older adults. J Am Geriatr Soc 2012;60:2326-2332.

20. Rosow I, Breslau N. A Guttman health scale for the aged. J Gerontol 1966;21:556-559.

21. Nagi SZ. An epidemiology of disability among adults in the United States. Milbank Mem Fund Q Health Soc 1976;54:439-467.

22. Kang $\mathrm{Y}, \mathrm{Na} \mathrm{DL}, \mathrm{Hahn} \mathrm{S}$. A validity study on the Korean Mini-Mental State Examination (K-MMSE) in dementia patients. J Korean Neurol Assoc 1997;15:300-308.

23. Jang IY, Lee S, Kim JH, et al. Lack of association between circulating apelin level and frailty-related functional parameters in older adults: a cross-sectional study. BMC Geriatr 2020;20:420.

24. Searle SD, Mitnitski A, Gahbauer EA, Gill TM, Rockwood $\mathrm{K}$. A standard procedure for creating a frailty index. BMC Geriatr 2008;8:24.

25. Fried LP, Tangen CM, Walston J, et al. Frailty in older adults: evidence for a phenotype. J Gerontol A Biol Sci Med Sci 2001;56:M146-M156.

26. Kroenke K, Spitzer RL, Williams JB. The Patient Health Questionnaire-2: validity of a two-item depression screener. Med Care 2003;41:1284-1292.

27. Won CW, Lee S, Kim J, et al. Korean frailty and aging cohort study (KFACS): cohort profile. BMJ Open 2020;10:e035573.

28. Mokkink LB, Terwee CB, Patrick DL, et al. The COSMIN checklist for assessing the methodological quality of studies on measurement properties of health status mea- 
surement instruments: an international Delphi study. Qual Life Res 2010;19:539-549.

29. World Medical Association. World Medical Association Declaration of Helsinki. Ethical principles for medical research involving human subjects. Bull World Health Organ 2001;79:373-374.

30. Mandrekar JN. Receiver operating characteristic curve in diagnostic test assessment. J Thorac Oncol 2010;5:13151316.

31. Jung HW, Jin T, Baek JY, et al. Functional age predicted by electronic short physical performance battery can detect frailty status in older adults. Clin Interv Aging 2020;15:2175-2182.

32. Jeong SM, Shin DW, Han K, et al. Timed up-and-go test is a useful predictor of fracture incidence. Bone 2019;127:474-481.

33. Jung HW, Jang IY, Lee CK, et al. Usual gait speed is associated with frailty status, institutionalization, and mortality in community-dwelling rural older adults: a longitudinal analysis of the Aging Study of Pyeongchang Rural Area. Clin Interv Aging 2018;13:1079-1089.

34. Jung HW, Kim S, Jang IY, Shin DW, Lee JE, Won CW. Screening value of timed up and go test for frailty and low physical performance in Korean older population: the Korean Frailty and Aging Cohort Study (KFACS). Ann Geriatr Med Res 2020;24:259-266.

35. Ga H, Won CW, Jung HW. Use of the Frailty Index and FRAIL-NH Scale for the assessment of the frailty status of elderly individuals admitted in a long-term care hospital in Korea. Ann Geriatr Med Res 2018;22:20-25.

36. Ellis G, Whitehead MA, Robinson D, O'Neill D, Langhorne P. Comprehensive geriatric assessment for older adults admitted to hospital: meta-analysis of randomised controlled trials. BMJ 2011;343:d6553.

37. Han SJ, Jung HW, Lee JH, et al. Clinical Frailty Scale, K-FRAIL questionnaire, and clinical outcomes in an acute hospitalist unit in Korea. Korean J Intern Med 2021;36:1233-1241. 


\section{Supplementary Table 1. Composition of 50 -item CGA-FI in this study}

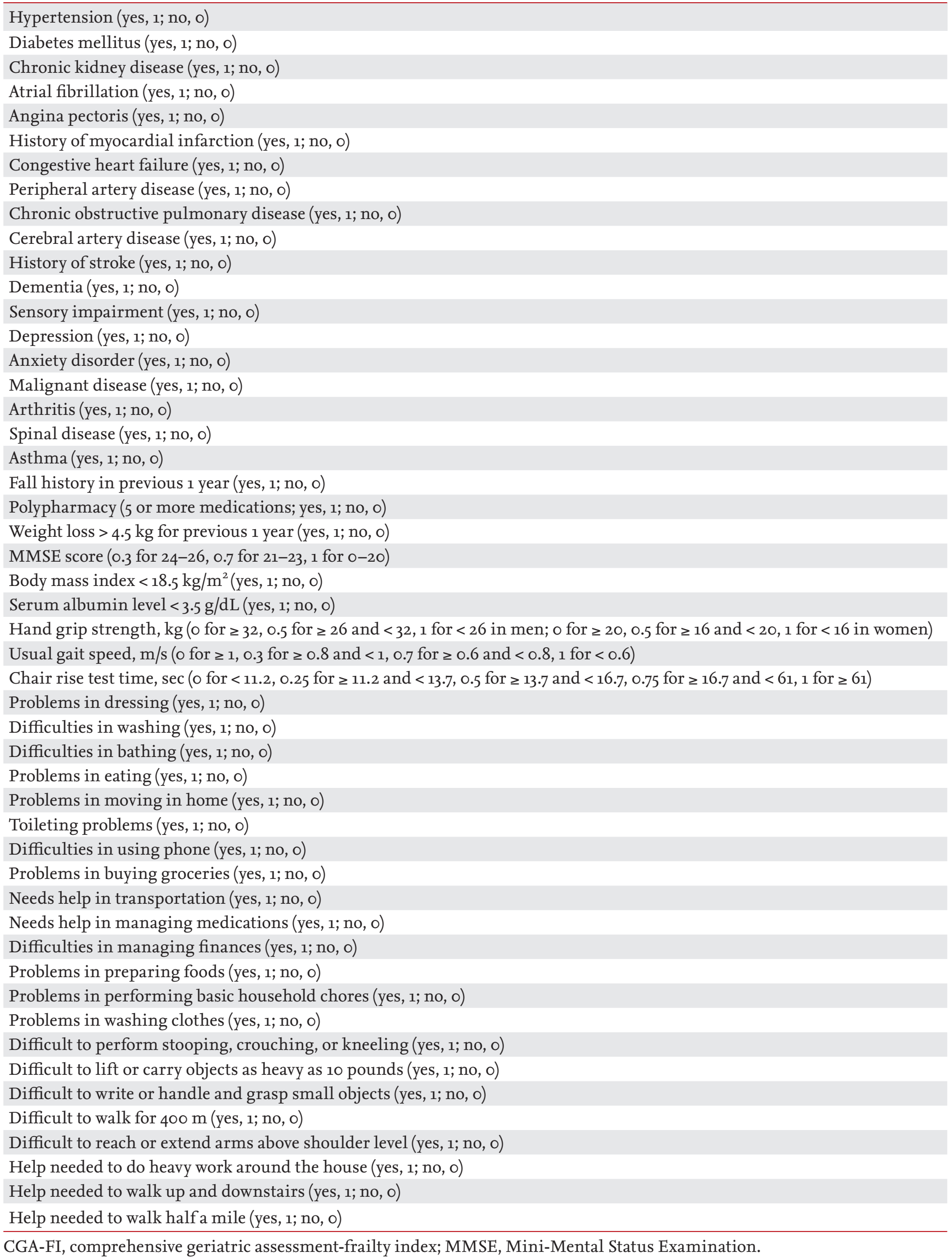


Supplementary Table 2. Clinical Frailty Scale

\begin{tabular}{|c|c|c|c|}
\hline$\square$ & 1 & $\begin{array}{l}\text { 매우 건강 } \\
\text { (Very Fit) }\end{array}$ & $\begin{array}{l}\text { 강건하고, 활동적이며, 활력이 넘치고, 의욕이 넘치는 사람. 보통 규칙 } \\
\text { 적으로 운동하며, 동년배에서 가장 건강한 편. }\end{array}$ \\
\hline$\square$ & 2 & 건강(Well) & $\begin{array}{l}\text { 현재 활동적인 질병, 증상은 없지만 매우 건강한 상태는 아님. 가끔(특 } \\
\text { 정 계절 한정 등) 격렬한 활동 혹은 운동을 함. }\end{array}$ \\
\hline$\square$ & 3 & $\begin{array}{l}\text { 건강관리 우수 } \\
\text { (Managing Well) }\end{array}$ & $\begin{array}{l}\text { 의학적 문제를 비교적 잘 관리하고 있으나 일상적인 활동(걷기 등) 이 } \\
\text { 상의 다른 격렬한 활동을 하지 않는 사람. }\end{array}$ \\
\hline$\square$ & 4 & $\begin{array}{l}\text { 아주 경미한 허약 } \\
\text { (Living with very } \\
\text { mild frailty) }\end{array}$ & $\begin{array}{l}\text { 일상생활에 타인에게 도움을 받을 정도는 아니나, 본인의 상태로 인해 } \\
\text { 활동이 제한되는 경우가 많음. 활동이 느려지거나, 일과중에 피곤함을 } \\
\text { 느끼는 증상이 대표적. 생활에 타인의 도움이 서서히 필요해지는 상태. }\end{array}$ \\
\hline$\square$ & 5 & $\begin{array}{l}\text { 경미한 허약 } \\
\text { (Mildly Frail) }\end{array}$ & $\begin{array}{l}\text { 행동 둔화의 양상을 보이며, 다소 어려운 도구적 일상생활 수행에는 도 } \\
\text { 움이 필요함. 대부분의 경미한 허약을 가진 사람들은 점차 쇼핑, 야외 } \\
\text { 에서 혼자 걷는 것, 식사 준비, 집안일등을 수행하기 어려워지게 됨. }\end{array}$ \\
\hline$\square$ & 6 & $\begin{array}{l}\text { 중등도 허약 } \\
\text { (Moderately Frail) }\end{array}$ & $\begin{array}{l}\text { 모든 외부활동과 집안일에 도움이 필요함. 실내에서는 계단 오르기, 목 } \\
\text { 욕 등을 혼자 할 수 없는 경우가 많고 옷 입기에도 약간의 보조가 필요 } \\
\text { 할 수 있음. }\end{array}$ \\
\hline$\square$ & 7 & $\begin{array}{l}\text { 중증 허약 } \\
\text { (Severely Frail) }\end{array}$ & $\begin{array}{l}\text { 신체적 혹은 인지적인 이유로 타인에게 완전히 의존하고 있으나 상태가 } \\
\text { 안정적이고 사망 위험(6개월 이내)도 높지 않아 보임. }\end{array}$ \\
\hline$\square$ & 8 & $\begin{array}{l}\text { 초고도 허약 } \\
\text { (Very Severely Frail) }\end{array}$ & $\begin{array}{l}\text { 수명이 얼마 남지 않은 상태로 일상생활을 타인에게 전적으로 의존함. } \\
\text { 사소한 질병에서도 회복하기 어려움. }\end{array}$ \\
\hline$\square$ & 9 & $\begin{array}{l}\text { 불치병 환자 } \\
\text { (Terminally III) }\end{array}$ & $\begin{array}{l}\text { 임종이 얼마 남지 않은 상태. 암 등 두드러지는 기저질환에 의해 6개월 } \\
\text { 이하의 기대수명 상태. }\end{array}$ \\
\hline
\end{tabular}

Adapted from Rockwood et al. [5]. 